\title{
Isolation of microsatellite markers for Bletilla striata and cross-amplification in other related species
}

\author{
Wu Ming-Kai ${ }^{1,2 \star}$, Li Jing ${ }^{1,2}$, Liu Zuo-Yi ${ }^{2}$, Luo Yi-Bo ${ }^{3}$ and Bai Wei-Ning ${ }^{3}$ \\ ${ }^{1}$ Modern Chinese Medical Materials Development of Guizhou Province, Guizhou Key Laboratory for Agricultural \\ Biotechology, Guiyang 550002, China. \\ ${ }^{2}$ State Key Laboratory of Environmental Geochemistry, Institute of Geochemistry, Chinese Academy of Sciences, \\ Guiyang 550002, China. \\ ${ }^{3}$ State Key Laboratory of Systematic and Evolutionary Botany, Institute of Botany, Chinese Academy of Sciences, \\ Beijing 100093, China.
}

Accepted 24 October, 2013

\begin{abstract}
Bletilla is a temperate, terrestrial genus of orchids containing 6 species. For the species whose whole genome is unknown, we used magnetic bead hybridization method to develop microsatellite Simple Repeat Polymorphoresis (SSR) for Bletilla striata and 9 primer sets were characterized in two wild populations of $B$. striata and one wild population of Bletilla ochracea. The number of alleles per locus ranged from 1 to 12. The expected and observed heterozygosities ranged from 0 to 0.7646 and 0 to 0.950 in $B$. striata, respectively. In B. ochracea, the expected and observed heterozygosities ranged from 0.296 to 0.871 and 0.05 to 1 , respectively. The 9 pairs of primers we designed can be used to distinguish different ecotypes and species, and might be used for other subspecies or species in genera Bletilla.
\end{abstract}

Key words: Bletilla striata, cross-species amplification, simple repeat polymorphoresis (SSR).

\section{INTRODUCTION}

The genus Bletilla, composting about six species, is endemic to Asia with a distribution pattern from $\mathrm{N}$ Myanmar and Indochina through China to Japan. The usage of the plants of Bletilla, mainly $B$. striata (Thunb.) Reichb. f., includes art (Chinese painting and writing), the production of porcelain, and medicine (Lawler, 1984), as well as vegetable dyes for dyeing cloth in some minority people in Guizhou and Yunnan Province, China (Luo, person observation). Those species are also commonly used as a horticultural subject covering both indoors and out cultivation in North American and European areas (Pridgeon, 2005). Recently, B. striata has been reported to be able to suppress various weed species (Sakuno et al., 2010). As the traditional herb medicine using more than 1500 years, pseudobulbs of Bletilla have been widely used in Eastern Asian countries to treat alimentary canal mucosal damage, ulcer, bleeding, bruises and burns. The pseudobulbs also show antibacterial, antiinflammatory, antiphlogistic and demulcent properties, and thus use in treating pneumonophthisis, pneumonorrhagia, tuberculosis and haemorrhage of the stomach or lung (Wang et al., 2006). Moreover, it is suggested that cationic polysaccharide from $B$. strata can serve as a non-viral nucleotide drug delivery vehicle for oligonucleoide or siRNA targeting to immunology system (Dong et al., 2009). Apparently, there is a huge potential demand for the pseudobulbs of Bletilla in future. At present, the cultivation of Bletilla is only limited to the temperature areas of North America and Europe for the horticultural purpose (Pridgeon, 2005), and the using of 
pseudobulbs of Bletilla for other purpose especially for medicinal purpose is basically based on wild resources.

Undoubtedly, the wild resource of Bletilla will rapidly decrease in Eastern Asian Countries due to over collections as well as habitat destruction and fragmentation (Chun and Chun, 2005). The conflict between the great market demand for the pseudobulbs of Bletilla and the decreased wild resource has necessitated the breeding of cultivars for high yields, high concentrations of active components and high resistance to diseases. Unfortunately, no cultivar has been bred so far and selections of superior individuals meeting the requirements are now underway from field and hybrid progenies. Molecular marker - assisted selection has become routine in cultivar breeding, and great efforts have been made to develop molecular markers such as microsatellites. More important, microsatellite markers have often been used for genetic diversity studies due to their desirable genetic attributes like hyper-variability, wide genomic distribution, co-dominant inheritance, reproducibility, multi-allelic nature and chromosome specific location (Singh et al., 2010; Tang et al., 2012). Here, we describe microsatellite loci which developed from $B$. striata and test the transferability of those markers to other related species. These loci were useful for further breeding superior cultivars and studies of genetic diversity, and contribute to knowledge on conservation of genus Bletilla.

\section{MATERIALS AND METHODS}

Genomic DNA of leaves of $B$. striata sampled from valley in Guiyang City, Guizhou Province, China (26 29' 46" N, 106 39' 39" E) was extracted using a plant genomic DNA Kit (Tiangen, Beiing, China). First, total genomic DNA was completely digested with the Msel restriction enzyme (New England Biolabs, Beverly, Massachusetts, USA), and then ligated to an Msel adapter pair (5'TACTCAGGACTCAT-3'/5'-GACGATGAGTCCTGAG-3') with T4 DNA ligase (New England Biolabs) in a $30 \mu \mathrm{L}$ reaction mixture. Tenfold diluted digestion-ligation mixture was amplified with adaptor-specific primers Msel-N (5'-GATGAGTCCTGAGTAAN-3') in $20 \mu \mathrm{L}$ reactions with the following conditions: 3 min denaturation at $95^{\circ} \mathrm{C}$; followed by 26 cycles of $30 \mathrm{~s}$ denaturation at $94^{\circ} \mathrm{C}, 1 \mathrm{~min}$ annealing at $53^{\circ} \mathrm{C}$, and 1 min extension at $72^{\circ} \mathrm{C}$; with a final extension of $72^{\circ} \mathrm{C}$ for $5 \mathrm{~min}$ and then were enriched for microsatellites with a 5'-biotinylated $(A G)_{15}$ probe. Thirdly, using adaptorspecific primers amplified enriched fragments again and using a PCR Purification Combo Kit (BioTeke, Beijing, China) purified it. Finally, the cleaned DNA fragments were ligated into the pEASYT1vector (Promega, USA), and transformed into competent cells of trans1-T1 Phage Resistant Chemically (Transgen, Beijing, China). Hundreds of positive clones amplified by PCR, and 95 of these, with a size range of 500 to $1000 \mathrm{bp}$, were sequenced with an $\mathrm{ABI}$ PRISM 3730 DNA sequencer (Applied, Biosystems, USA). The sequences which contained SSR were designed specific primers using primer primer 5.0 (Lalitha, 2000) and thirty had sufficient regions to design primer.

All primer pairs were assayed in individuals PCR and run on $1 \%$ agarose gels. Thirteen primer pairs have specific and right loci. Then, to utilize fluorescently labeled M13 primer for sequencing, the forward primer of each pair added an M13 sequence (5'TGTAAAACGACGGCCAGT-3') to its 5' (Schuelke, 2000). Using the fluorescently labeled primer for amplification, nine primer pairs showed clear bands and expected size. The $25 \mu \mathrm{l}$ volumes PCR mix contained 4 pmol reverse primer and FAM/ HEX/ TAMRA$\mathrm{M} 13(-21)$ primer, $1 \mathrm{pmol}$ of the forward primer, $12.5 \mathrm{~mm}$ Tris- $\mathrm{HCl}$ (pH 8.3), $62.5 \mathrm{~mm} \mathrm{KCl}, 1.875 \mathrm{~mm} \mathrm{MgCl}_{2}, 0.25 \mathrm{~mm}$ of each dNTP, $0.75 \mathrm{U}$ DNA polymerase (TakaraTaq) and $50 \mathrm{ng}$ template DNA. PCR amplification were done as follows: $94^{\circ} \mathrm{C}$ for $5 \mathrm{~min}$, then 30 cycles at $94^{\circ} \mathrm{C}$ for $30 \mathrm{~s}$, specific annealing temperature (Table 1) for $45 \mathrm{~s}, 72^{\circ} \mathrm{C}$ for $45 \mathrm{~s}$, followed by 8 cycles at $94^{\circ} \mathrm{C}$ for $30 \mathrm{~s}, 53^{\circ} \mathrm{C}$ for $45 \mathrm{~s}, 72^{\circ} \mathrm{C}$ for $1 \mathrm{~min}$, and a final extension at $72^{\circ} \mathrm{C}$ for $10 \mathrm{~min}$. The nine microsatellite loci were characterized using 54 wild samples were collected from three Sites in China: 14 samples of $B$. striata from valley in Guiyang, Guizhou, POP- GY: $26^{\circ} 29^{\prime} 46^{\prime \prime} \mathrm{N}, 106^{\circ} 39^{\prime}$ 39" E; 20 samples of $B$. striata from valley in Xinning, Hunan, POP$X N$ : $26^{\circ} 25^{\prime} 42^{\prime \prime} \mathrm{N}, 110^{\circ} 50^{\prime} 30^{\prime \prime} \mathrm{E} ; 20$ samples of $B$. ochracea from valley in Qingzhen, Guizhou, POP-QZ: 26 $36^{\prime} 2^{\prime \prime} \mathrm{N}, 106^{\circ} 28^{\prime} 16^{\prime \prime} \mathrm{E}$. The PCR amplification was same to the aforementioned described. Nine primer pairs tested for polymorphism on an ABIPRISM 3730 Genetic Analyzer and using GeneMapperv4.0 software (Applied Biosystems) analyzed the result.

The numbers of alleles per locus, observed and expected heterozygosities, and deviations from Hardy-Weinberg equilibrium (HWE) were estimated using FSTAT version 2.9.3 (Gouldet, 2001).

\section{RESULTS}

The newly developed microsatellite loci showed high levels of polymorphism in $B$. striata. The microsatellite markers can be used to evaluate the genetic diversity and infer evolutionary processes in natural populations, which should be useful for developing the appropriate conservation strategies for $B$. Striata.

\section{DISCUSSION}

Microsatellite markers are based on the amplification of internal sequences between microsatellites [intersimple sequence repeat (ISSR) markers] using PCR and then looking for microsatellite loci contained within these sequences, taking into account that microsatellites are generally clustered within the plant genome, and microsatellite markers have been proven useful in assessing genetic diversity of populations in different species (López-Roberts et al., 2012; Caitlin et al., 2013). In the present study, the result can draw that BJ67 were monomorphic in these two $B$. striata population, but polymorphic in $B$. ochracea. BJ311 and BJ120 failed to amplify in $B$. ochracea. In $B$. striata and $B$. ochracea, the number of alleles per locus ranged from 1 to 12 and the mean number of alleles per species was 4.33 and 4.14 , respectively (Table 2). The expected and observed heterozygosities ranged from 0 to 0.7646 and 0 to 0.950 in $B$. striata, respectively. In $B$. ochracea, the expected and observed heterozygosities ranged from 0.296 to 0.871 and 0.05 to 1 , respectively. The 9 pairs of primers we designed can be used to distinguish different ecotypes and species, and might be used for other subspecies or species in genera Bletilla, which would provide for implementing concrete protection strategy and/or tagging the very right medical herbs. 
Table 1. The characteristics of nine microsatellite loci in B. striata.

\begin{tabular}{|c|c|c|c|c|c|}
\hline Locus & Primers sequences $\left(5-3^{\prime}\right)$ & Repeat motif & Size range (bp) & $\mathrm{Ta}\left({ }^{\circ} \mathrm{C}\right)$ & GenBank accession No. \\
\hline \multirow[t]{2}{*}{ BJ109 } & F: CTATTATTCCTCCTCGTTTG & $(\mathrm{GA})_{13}$ & $160-174$ & 54 & JQ965919 \\
\hline & R: CTAGCCTACCAAGTAGTTCC & & & & \\
\hline \multirow[t]{2}{*}{ BJ98 } & F: GGCTAACCCATAATTGATC & $(G A)_{23}$ & $258-310$ & 58 & JQ965917 \\
\hline & R: CTTTCATTGAGGTGGACTT & & & & \\
\hline \multirow[t]{2}{*}{ BJ70 } & F: CACGAACAGCCACTATCA & $(\mathrm{GA})_{8}$ & 271-301 & 58 & JQ965914 \\
\hline & R: TTACAAGCCTCCCAАTCT & & & & \\
\hline \multirow[t]{2}{*}{ BJ120 } & F: CCATTACCAACCGTGGAG & $(\mathrm{GA})_{10}$ & $112-126$ & 58 & JQ965916 \\
\hline & R: GTCGGACGAAAGTGAGCC & & & & \\
\hline \multirow[t]{2}{*}{ BJ311 } & F: CCAAAGTGATAACGGAAGG & $(\mathrm{GA})_{11}$ & 343 & 54 & JQ965913 \\
\hline & R: TTGAATCCAAGAAGTGCC & & & & \\
\hline \multirow[t]{2}{*}{ BJ303 } & F: TCAGTTTGTCGCTTCTATG & $(\mathrm{TC})_{8}$ & $111-131$ & 54 & JQ965918 \\
\hline & R: ATCCTGAATCTGGGGCTA & & & & \\
\hline \multirow[t]{2}{*}{ BJ67 } & F: CCGATGTGGAGGTAGAGC & $(\mathrm{TTC})_{5}$ & 237 & 56 & JQ965915 \\
\hline & R: CGGAAACGGAAGAAGAAG & & & & \\
\hline \multirow[t]{2}{*}{ BJ68 } & F: CAAAGCAAACTGGACGAA & $(\mathrm{GA})_{8}$ & $129-133$ & 54 & JQ965921 \\
\hline & R: CCATAATCACTTGGAACCC & & & & \\
\hline \multirow[t]{2}{*}{ BJR100 } & F: GCTGAGGACAGAAGGGAG & $(A G)_{10}$ & $298-304$ & 58 & JQ965920 \\
\hline & R: AGTAGAAATCATCGCACAA & & & & \\
\hline
\end{tabular}

Table 2. Results of initial primer screening in two populations of Bletilla striata and one populations of Bletilla ochracea. Shown for each primer pair are the number of Alleles $(\mathrm{A})$, average observed $\left(H_{0}\right)$ and expected heterozygosity $\left(H_{e}\right)$.

\begin{tabular}{|c|c|c|c|c|c|c|c|c|c|}
\hline \multirow{2}{*}{ Locus } & \multicolumn{3}{|c|}{$P O P-G Y(N=20)$} & \multicolumn{3}{|c|}{$P O P-X N(N=14)$} & \multicolumn{3}{|c|}{$P O P-Q Z(N=20)$} \\
\hline & A & $H_{0}$ & $H_{e}$ & A & $H_{o}$ & $H_{e}$ & A & $H_{o}$ & $H_{e}$ \\
\hline BJ68 & 2 & 0.300 & 0.262 & 2 & 0.0714 & 0.0714 & 3 & 0.700 & 0.555 \\
\hline BJ98 & 6 & 0.950 & 0.751 & 7 & 0.5714 & 0.6799 & 12 & 0.800 & 0.871 \\
\hline BJ109 & 3 & 0.450 & 0.676 & 6 & 0.5714 & 0.7646 & 3 & 0.050 & 0.432 \\
\hline BJ303 & 2 & 0.350 & 0.296 & 2 & 0.1429 & 0.1376 & 5 & 0.450 & 0.706 \\
\hline BJ311 & 1 & 0 & 0 & 1 & 0 & 0 & na & & \\
\hline BJ67 & 1 & 0 & 0 & 1 & 0 & 0 & 2 & 0.350 & 0.296 \\
\hline BJ70 & 2 & 0.550 & 0.409 & 4 & 0.3571 & 0.5608 & 2 & 0.500 & 0.431 \\
\hline BJ120 & 2 & 0.750 & 0.481 & 5 & 0.7143 & 0.7249 & na & & \\
\hline BJR100 & 2 & 0.850 & 0.512 & 4 & 0.8571 & 0.5767 & 2 & 1.000 & 0.513 \\
\hline
\end{tabular}

\section{REFERENCES}

Caitlin D. A. Ishibashi, Anthony R. Shaver, David P. Perrault, Stephen D. Davis, and Rodney L. Honeycutt. (2013). Isolation of Microsatellite Markers in a Chaparral Species Endemic to Southern California, Ceanothus megacarpus (Rhamnaceae). Appl. Plant Sci. 1(5):1200393.

Chung MY, Chung MG (2005). Pollination biology and breeding systems in the terrestrial orchid Bletilla striata. Plant Sys. Evol 252:1-9.
Dong L, Xia SH, Luo YB, Diao HJ, Zhang JN, Chen JN, Zhang JF (2009). Targeting delivery oligonucleotide into macrophages by cationic polysaccharide from Bletilla striata successfully inhibited the expression of TNF- $\alpha$. J. Controlled Release 134:214-220.

Gouldet J (2001). FSTAT: A program to estimate and test gene diversities and fixation indices (version2.9.3). Available from URL: http://www.unil.ch/izea/softwares/fstat.html.

Lawler LJ (1984). Ethbnobotany of the Orchidaceae. In J. Arditti (ed.), Orchid Biology: Rev. Perspect, 3: 27 - 149. Cornell University 
Press, Ithaca, New York, USA.

Lalitha S (2000). Primer Primer 5.0. Biotech Software and Internet Report 1:270 -272.

Min Tang, Chun-Xia Zeng, Yu-Fen Bi, Jun-Bo Yang. ( 2012). Microsatellite markers for the Chinese endangered and endemic orchid Cymbidium tortisepalum (Orchidaceae). Am. J. Bot. 99: e11e13.

López-Roberts MC, Almeida PR, Oliveira EJ, van den Berg C (2012). Microsatellite marker development for the threatened orchid Masdevallia solomonii (Orchidaceae). Am. J. Bot. 99(2): e66-e68.

Pridgeon AM, Cribb PJ, Chase MW, Rasmussen FN (2005). Genera Orchidacearum, Volume. 4, Epidendroideae (Part 1). Oxford University Press, New York, USA.

Schuelke M (2000). An economic method for the fluorescent labeling of PCR fragments. Nat. Biotechnol. 18:233-234.
Singh RK, Mishra SK, Singh SP, Mishra N, Sharma ML (2010). Evaluation of microsatellite markers for genetic diversity analysis among sugarcane species and commercial hybrids. Austr. J. Crop Sci. 4:116-125

Sakuno EM, Kamo TI, Takemura T, Sugie H, Hiradte S, Fujii Y (2010). Contribution of militarine and dactylorhin $A$ to the plant growthinhibitory activity of a weed-suppressing orchid, Bletilla striata. Weed Biol. Managt 10:202-207.

Wang CM, Sun JT, Luo YB, Xue WH, Diao HJ, Dong L, Chen JN, Zhang JF. (2006). A polysaccharide isolated from the medicinal herb Bletilla striata induces endothelial cells proliferation and vascular endothelial growth factor expression in vitro. Biotechnology Letters 28:539-543. 